\title{
Combined Impressed Current Cathodic Protection and FRCM Strengthening for Corrosion-Prone Concrete Structures
}

DOI:

10.1061/(ASCE)CC.1943-5614.0000949

\section{Document Version}

Accepted author manuscript

Link to publication record in Manchester Research Explorer

Citation for published version (APA):

Su, M-N., Wei, L., Zhu, J-H., Ueda, T., Guo, G-P., \& Xing, F. (2019). Combined Impressed Current Cathodic Protection and FRCM Strengthening for Corrosion-Prone Concrete Structures. Journal of Composites for Construction. https://doi.org/10.1061/(ASCE)CC.1943-5614.0000949

\section{Published in:}

Journal of Composites for Construction

\section{Citing this paper}

Please note that where the full-text provided on Manchester Research Explorer is the Author Accepted Manuscript or Proof version this may differ from the final Published version. If citing, it is advised that you check and use the publisher's definitive version.

\section{General rights}

Copyright and moral rights for the publications made accessible in the Research Explorer are retained by the authors and/or other copyright owners and it is a condition of accessing publications that users recognise and abide by the legal requirements associated with these rights.

\section{Takedown policy}

If you believe that this document breaches copyright please refer to the University of Manchester's Takedown Procedures [http://man.ac.uk/04Y6Bo] or contact uml.scholarlycommunications@manchester.ac.uk providing relevant details, so we can investigate your claim.

\section{OPEN ACCESS}


Mei-ni $\mathrm{SU}^{1}$, Liangliang $\mathrm{WEI}^{2}$, Ji-Hua $\mathrm{ZHU}^{3 *}$, Tamon $\mathrm{UEDA}^{4}$, Guan-ping $\mathrm{GUO}^{5}$, Feng XING,

"Combined Impressed Current Cathodic Protection and FRCM Strengthening for Corrosion-Prone

Concrete Structures", Journal of composites for construction, ASCE, 23(4):04019021.

\title{
Combined impressed current cathodic protection and FRCM
}

\section{strengthening for corrosion-prone concrete structures}

\author{
Mei-ni SU ${ }^{1}$, Liangliang $\mathrm{WEI}^{2}$, Ji-Hua ZHU ${ }^{3 *}$, Tamon $\mathrm{UEDA}^{4}$, Guan-ping $\mathrm{GUO}^{5}$, Feng XING ${ }^{6}$, \\ ${ }^{1}$ Lecturer, School of Mechanical, Aerospace and Civil Engineering, University of Manchester, \\ Manchester, UK, M1 3NJ. \\ ${ }^{2} \mathrm{PhD}$ Candidate, Laboratory of Engineering for Maintenance System, College of Engineering, \\ Hokkaido Univ., Sapporo 060-8628, Japan. \\ ${ }^{3}$ Professor, Guangdong Province Key Laboratory of Durability for Marine Civil Engineering, School \\ of Civil Engineering, Shenzhen University, Shenzhen, Guangdong 518060, PR China. (Corresponding \\ author: zhujh@ szu.edu.cn) \\ ${ }^{4}$ Professor, Laboratory of Engineering for Maintenance System, Faculty of Engineering, \\ Hokkaido Univ., Sapporo 060-8628, Japan. \\ ${ }^{5}$ Master Graduate, Guangdong Province Key Laboratory of Durability for Marine Civil Engineering, \\ School of Civil Engineering, Shenzhen University, Shenzhen, Guangdong 518060, PR China. \\ ${ }^{6}$ Professor, Guangdong Province Key Laboratory of Durability for Marine Civil Engineering, School \\ of Civil Engineering, Shenzhen University, Shenzhen, Guangdong 518060, PR China.
}

Abstract: This study introduces the use of the combined impressed current cathodic protection structural strengthening (ICCP-SS) as a technique for repairing reinforced concrete (RC) structures that have been subjected to chloride-induced corrosion. The development of this technique is based on the combination of a carbon fiber mesh (CF-MESH) and a polymer-modified cementitious matrix to produce a carbon fiber reinforced cementitious matrix (C-FRCM). Firstly, the effects of different types and amounts of high molecular weight polymer and short chopped carbon fibers on the flexural and compressive strength, conductivity and shear strength of a matrix with concrete substrate were investigated in order to find the optimum ingredients required for a high-performance cementitious matrix. Secondly, a shaped CF-MESH was bonded onto the surface of a concrete cube using the aforementioned optimized cementitious matrix. The impressed current cathodic protection (ICCP) technique was then applied to the specimens by using different current densities with the CF-MESH as the anode. During the 
protection period, the protection conditions of rebars subjected to ICCP were assessed by analyzing a variety of electrochemical parameters. Thirdly, single shear tests were conducted; the shear strengths and failure modes of the specimens were obtained and compared in order to evaluate the effects of the ICCP on shear stress transfer. The results show that the proposed technique based on the newly proposed C-FRCM composite is able to provide effective cathodic protection as well as shear stress transfer behavior to RC structures subjected to chloride-induced corrosion, leading to an improvement with respect to structural durability.

Keywords: C-FRCM; reinforced concrete; single shear test; impressed current cathodic protection; structural strengthening; corrosion

\section{Introduction}

The corrosion of steel reinforcement is one of the key reasons behind the degradation of reinforced concrete (RC) structures, while a chloride environment is one of the main conditions causing the corrosion of the rebars (Mehta 1991; Raupach 1996). It has seemed practical to reduce the water/cement ratio to improve the compactness of the concrete, or alternatively to increase the thickness of the concrete cover to reduce the migration rate of chloride ions to the rebars. Both methods could be considered in design process to extend the service life of RC structures. However, in terms of existing and seriously degraded RC structures, some other strengthening techniques are needed in order to improve their service performance.

Generally speaking, methods used to impede rebar corrosion help to improve the service performance of degraded RC structures. It has been proven that cathodic protection is an effective 
way of preventing further corrosion to rebars. The impressed current cathodic protection (ICCP) technique is the one of the effective ways of ensuring the electrochemical corrosion protection of structures in a chloride - contaminated environment (ISO-12696, 2016; Zhang et al., 2016). The principle of ICCP is to apply external current through concrete to steel, and cathodically polarize steel to a more negative potential, at which corrosion is unlikely to occur thermodynamically. Once the potential of steel is reduced sufficiently by cathodic polarization, the steel enters the immunity zone where corrosion stops. During ICCP, iron dissolution on the surface of steel is hindered and only oxygen oxidation occurs. Meanwhile, the structural strengthening (SS) technique can directly improve the behavior of existing degraded structures under loading. One of the most common ways of providing structural strengthening is by applying fiber reinforced polymers (FRPs) to strengthen existing structures (Saadatmanesh and Malek 1998). However, existing structures subjected to chloride-induced corrosion cannot be systematically repaired simply by using the ICCP method on its own, or indeed the structural strengthening (SS) method on its own. Although ICCP prevents the further corrosion of the reinforcement, it cannot help to recover the deficiency of the loading capacities due to previous degradation. The loading capacities of RC structures cannot, therefore, be improved by the ICCP. On the other hand, if FRPs are used to strengthen the existing degraded corrosion-prone structures, they can help them recover their loading capacity; however, the further corrosion of rebars will continue due to the internal presence of chloride ions, so the strengthened structures will still experience a rapid decrease in loading capacity. For these structures, although using FRP strengthening method can temperately improve their loading capacities, the steel rebars inside of the structures could be continuously corroded, leading to further durability issue such as the cracking of concrete and 
fracture of FRP (Michel et al., 2014; Zhao et al., 2016; Shi et al., 2018) as well as the reduction of debonding strength of FRP-concrete interface (Zhang et al., 2016). Therefore, even though in serious damaged structures, it is practically assumed that there is no reinforcement contribution to the loading resistance for design purpose, the ICCP treatment is also needed for corrosion-prone concrete structures. Otherwise, further FRP strengthening process will be needed. To conclude, in order to improve the durability of corroded RC structures, both ICCP and structural strengthening intervention methods are needed.

Carbon fiber reinforced polymer (CFRP) possesses a high strength-to-weight ratio, good durability and a high fatigue resistance as well as other beneficial properties. It is a well-known material for retrofitting structures. In addition, it is also electrically conductive. Theoretically, any electrically conductive material could be the anode material in ICCP system. However, besides the electric conductivity, the successful application of ICCP also depends significantly upon the correct operation of the anodes, the cost of the anode material and their service life or rate of consumption due to a number of environmental and operational factors. The feasibility of using CFRP as the anode material in ICCP has been proven by Nguyen et al. (2012), Zhu et al. (2014a, 2014b), Lambert et al. (2015) and Verma and Goyal (2015). Though CFRP has ageing problem, the previous studies (Zhu et al. 2017) found that CFRP would not be damaged if the current density applied in the ICCP system is carefully chosen and the service life of CFRP anode could be up to 40 years. The CFRP degradation mechanism and its residual strength prediction have been investigated in Zhu et al. (2017). Based on the electrochemical behavior of CFRP, further studies also investigated the application of CFRP in the electrochemical chloride extraction of steel-reinforced concrete (Zhu et al. 2016) and in the recycling of carbon fibers (Sun et al. 2015). 
The present study uses carbon fiber mesh (CF-MESH) as a dual-functional material in order to combine cathodic protection and structural strengthening as an integrated retrofitting technique, termed as impressed current cathodic protection - structural strengthening (ICCP-SS). The ICCP-SS technique takes advantages of ICCP and SS, by preventing the further corrosion of re-bars and improving the loss of strength of RC structures subjected to corrosion in coastal environment or due to de-icing salt in winter seasons. The ICCP-SS technique is an efficient method to improve the durability of RC structures, and its application can help develop and maintain our infrastructure in a sustainable and low carbon manner. In order to achieve the favorable effects of ICCP and SS, the anode material or the strengthening material should be bonded onto the surface of RC structures (Pedeferri 1996; Dai et al. 2005), and the electrical conductivity path must exist between corroded rebars and anode. The bonding material commonly used for structural strengthening - organic epoxy resin is insulated, and consequently cannot be used in the ICCP-SS technique.

To solve this problem, the present study introduces the development of a new fiber reinforced cementitious matrix to bond the CF-MESH. The proposed cementitious matrix has its own advantageous characteristics such as affordable price, good electric conductivity, better durability, ease of installation, better fire resistance and ease of reversibility (that is, the ability to undo the repair without harming the original structure) (Montesi, 2015). In addition, both the cementitious matrix and concrete are inorganic materials that exhibit chemical, physical, and mechanical compatibility with the concrete or masonry substrate. By embedding a CF-MESH inside the cementitious matrix, a carbon fiber-reinforced cementitious matrix (C-FRCM) laminate is obtained (D’Ambrisi and Focacci 2011, D'Ambrisi et al. 2013, D'Ambrisi et al. 2015). The 
development of high-performance C-FRCM composites has recently attracted great research interests on the composite material optimization, property characterization and application for structural strengthening. (Awani et al. 2017, Escrig et al. 2017). In addition, a number of design guidelines and standards for the use of cementitious matrix composites became available (JSCE, 2008; ACI 549.4R, 2013; AC434, 2016; RILEM, 2016).

In this study, a new cementitious matrix for the purpose of ICCP-SS is proposed by investigating and comparing its electric conductivity, flexural, compressive and shear strengths. Single shear tests were conducted by using the optimized cementitious matrix to bond the CF-MESH onto RC structures, so that the behavior of the interface between C-FRCM composite and concrete can be assessed. The purposes of the present study are to propose an innovative solution to improve the durability of existing degraded RC structures using the C-FRCM composite, the effects of applied current on the mechanical properties of C-FRCM composite and the structural durability of the ICCP-SS system.

\section{Performance of the cementitious matrix}

\section{Experimental program}

\section{Materials of specimens}

This study investigates the effects of different types and amounts of high molecular weight polymer and short chopped carbon fibers on the flexural and compressive strength, conductivity and shear strength of cementitious matrix. The ingredients used in these cementitious matrices included: ordinary Portland cement 42.5R, which was used for the concrete substrate and the cementitious matrices throughout the experiments conducted during the course of this research, as 
well as silica fume, which was used in the cementitious matrices. A high-performance polycarboxylate superplasticizer was added to improve the workability of the cementitious matrix. Redispersible latex powder DY-5025 and styrene butadiene latex SBR 1006 were used in the tests to investigate the polymer-modified adoption. The $3 \mathrm{~mm}$ short chopped carbon fibers $\mathrm{K} 12$ were added to further improve the flexural and compressive strength and conductivity of the cementitious matrix. Carboxymethyl cellulose was used to fully disperse the short chopped carbon fibers. In addition, carbon fiber mesh with an inner spacing of $5 \mathrm{~mm} \times 5 \mathrm{~mm}$ was used in the C-FRCM, with its material properties being shown in Table 1.

\section{Tests}

The experimental program included first series tests carried out using different types and amounts of high molecular weight polymer and second series tests using different amounts of short chopped carbon fibers. In the first series tests, the high molecular weight polymer can be further divided into two types: redispersible polymer powder (WA) and styrene butadiene latex (WB), with the mix percentage being $20 \%, 30 \%$ or $40 \%$ of the total mass of the cement and silica fume. The detailed mixing proportions of the cementitious matrix in the first series of tests are shown in Table 2.

In order to further improve the performance of the cementitious matrix, in the second series of tests, different amounts of short chopped carbon fibers were added to the optimal ingredients obtained from the first series of tests. The amount of short chopped carbon fibers was chosen as $1 \%$ (WC-1), 2\% (WC-2) or 3\% (WC-3) of the mass of the cement as shown in Table 3. The preparation process of the polymer-modified inorganic cementitious matrix is as follows: (1) add 
162

163

the cement, silica fume, redispersible latex powder and short chopped carbon fibers as well as CMC into a container and mix for 2 minutes at low stirring speed in order to disperse fully; (2) dissolve the superplasticizer into a certain amount of water; (3) pour the superplasticizer solution and the remaining water into the mixture and stir for 2 minutes at low stirring speed; (4) add the defoamer into the slurry and continue to stir for 2 minutes at high stirring speed.

The dimensions of the test specimens, which were used to investigate the flexural and compressive strength and conductivity of the matrix, were $40 \mathrm{~mm} \times 40 \mathrm{~mm} \times 160 \mathrm{~mm}$. The flexural and compressive strength were tested (EN 196-1, 2005) after 7 days, 14 days and 28 days. The conductivity of the matrix was tested by the four-electrode method to measure its electric resistance (Chen et al. 2004), as shown in Fig. 1. The shear strength between the C-FRCM and concrete was obtained by means of typical single shear tests (Dai et al. 2005; Ueda and Dai 2005; Tran et al. 2014; Kabir et al. 2016) using a $100 \mathrm{~mm} \times 100 \mathrm{~mm} \times 100 \mathrm{~mm}$ concrete cube with a 28-day strength of 49.8 MPa. Please note that the compressive strength is the average value based on five test results with the coefficient of variation of 0.016 . The bond area was $70 \mathrm{~mm} \times 100 \mathrm{~mm}$ as shown in Fig. 2. The loading rate adopted in the tests was $0.08 \mathrm{~mm} / \mathrm{min}$. During tests, the loads were recorded at 1 -second intervals. The shear strength was obtained by dividing the ultimate load with the bond area.

\section{Results and discussion}

\section{First series of tests (ingredients with high molecular weight polymer)}

Table 4 shows the changes in the flexural and compressive strength and conductivity of the cementitious matrix over time. The flexural and compressive strength increased constantly over 
time. In the first series of tests, specimen WA-1 was found to reach the highest flexure capacity (7.1 MPa) and compression capacity (29.9 MPa) after 28 days. The conductivity of all the specimens was measured and found to be less than $0.1(\Omega \times \mathrm{m})^{-1}$, but far greater than the conductivity of concrete $\left(10^{-7} \sim 10^{-4}(\Omega \times \mathrm{m})^{-1}\right)$. Single shear tests were conducted on the specimens prepared using different types of cementitious matrix. Three different failure modes were observed, as shown in Fig. 3: (1) peeling failure within the concrete cube (DB) (see Fig. 3(a)); (2) debonding failure between the CF-MESH and the cementitious matrix (CB) (see Fig. 3(b)) and (3) mixed failure combining the above two failure modes $(\mathrm{DB}+\mathrm{CB})$ (see Fig. 3(c)). Table 4 summarizes the flexural and compressive strengths and the failure modes of the single shear tests. Mixing a certain amount of high molecular weight polymer - the redispersible polymer in the cementitious matrix could improve the interfacial strength significantly. For the cementitious matrix without high molecular weight polymer (W-0 and W-0\#), the average shear strength was $0.72 \mathrm{MPa}$, and the failure mode was debonding failure between the CF-MESH and the cementitious matrix (CB), as shown in Fig. 3(b). This failure mode did not fully utilize the strength of the CF-MESH (Ueda and Dai, 2005). By adding $20 \%$ redispersible polymer powder to the matrix (WA-1), the average shear strength increased to $1.20 \mathrm{MPa}$ and the failure mode became peeling failure within the concrete cube (DB), as in Fig. 3(a). The specimens with this failure mode were able to prevent debonding failure between the CF-MESH and the surrounding cementitious matrix and finally depend on the tensile strength of concrete (Ueda and Dai 2005). However, when the mixing amount of redispersible polymer powder increased, the shear strength started to decrease and the failure mode became CB, as shown in Fig. 3(b). When styrene butadiene latex was added, the failure mode was mixed mode $(\mathrm{DB}+\mathrm{CB})$, and the shear strength decreased as the amount of the styrene 
butadiene latex increased. The cementitious matrix with a certain amount of the redispersible polymer powder performed comparatively better than that containing the same amount of styrene butadiene latex. The results showed that the WA-1 specimen performed best in terms of flexural and compressive capacities.

\section{Second series of tests (ingredients with short chopped carbon fibers)}

In the literature on the subject, it was found that adding short chopped carbon fibers to the cementitious matrix improved its conductivity and structural behavior (Chung 2000, Badanoiu and Holmgren 2003). Therefore, in the second series of tests, which were based on the results of the WA-1 specimen obtained in the first series of tests, certain amounts of short chopped carbon fibers were added to the mix (WC). This was done to seek the possibility of further improving the flexural and compressive strengths, conductivity and shear strength of the cementitious matrix. In comparison to the previous tests, the WC specimens were found to have a much higher flexural strength (20 - 24.7 MPa), compressive strength (32.8 - 37.7 MPa) and conductivity (3.9 - $4.2(\Omega \times$ m) $)^{-1}$ ) after 28 days compared with the WA and WB specimens. As we can see from Table 4, the shear strength of the WC specimens was also found to be greater than the WA- 1 specimen. The average shear strength for WC-1 was found to be 1.49 MPa with the failure mode of DB. However, with an increase in the amount of short chopped carbon fibers, the average shear strength decreased slightly. When the mixing amount reached 3\%, the average shear strength became as low as $1.29 \mathrm{MPa}$ with the failure mode changing to $\mathrm{DB}+\mathrm{CB}$, as shown in Fig. 4 .

\footnotetext{
The results obtained in this study can be compared with similar investigations in literature.
} 
Carloni et al. (2015) conducted single-lap direct-shear tests on fiber reinforced cementitious matrix (FRCM) strips bonded to a concrete block. The shear strengths were found to be approximately between $0.27-0.35 \mathrm{MPa}$, with the failure mode as debonding at the matrix-fiber interface. It has also been reported by D'Ambrisi et al. (2013) that the shear strength between FRCM materials made out of a polyparaphenylene benzobisoxazole (PBO) mesh embedded in a cement-based matrix and concrete was between $0.38-1.16 \mathrm{MPa}$. The failure mode was also found to be debonding at the fiber/matrix interface after a considerable fiber/matrix slip. Recently, Ombres (2015) conducted a few single shear tests on the interface of FRCM and concrete, and found the shear strength to be approximately $0.20-0.75 \mathrm{MPa}$. Comparing the experimental average shear strengths from this study and those collected from the literature (D'Ambrisi et al. 2013, Tran et al. 2014, Ombres 2015, Carloni et al. 2015) shows that the proposed C-FRCM composite provides the greatest bonding strength.

To summarize, by assessing the flexural and compressive strengths, conductivity and shear strength of different polymer-modified inorganic cementitious matrices, the authors were able to conclude that the WC-1 ingredient had the better performance. The proposed cementitious material is electric conductive, while the mechanical properties satisfied the criteria set out in AC434 (2016) for cementitious material. The present paper uses the mix of the WC-1 matrix in the C-FRCM to develop the ICCP-SS technique for corroded RC structures.

\section{The performance of the ICCP-SS technique}

\section{Experimental program}

The test configuration is shown in Fig. 5(a). The dimensions of the test specimens were $150 \mathrm{~mm} \times$ 
$150 \mathrm{~mm} \times 150 \mathrm{~mm}$. Natural river sand, which had been passed through a sieve with 3.0-mm openings, was used as fine aggregate for all the concrete mixes. Its density and fineness modulus were provided by the manufacturer $-2.7 \mathrm{~g} / \mathrm{cm}^{3}$ and 2.8 , respectively. Crushed sandstone with a maximum size of $15 \mathrm{~mm}$ was used as a coarse aggregate and cleaned before being used. The compressive strengths of concrete were determined using $150 \times 150 \times 150 \mathrm{~mm}$ cube specimens and the 28-day compressive strength was 49.8 MPa. In addition, a certain amount of $\mathrm{NaCl}$, which was $3 \%$ of the mass of cement, was mixed as casting to simulate a chloride-contaminated environment. The ratio of chloride ions in the concrete was higher than the specified value in the specifications (ASTM 1990, ACI 2001, Dong et al. 2016). Deformed carbon steel bars of $16 \mathrm{~mm}$ in diameter were used as reinforcing steel. A layer of CF-MESH (the same as the mesh used in the first series tests) was bonded onto the concrete surface using the aforementioned optimized cementitious matrix (i.e. WC-1). The bond width and length of the C-FRCM were both equal to $100 \mathrm{~mm}$. Outside of the bond area, there was a $50 \mathrm{~mm}$ long region at the loading end to prevent local failure due to load concentration.

The CF-MESH and the embedded steel bars were connected to the positive and negative electrodes of a power supply, respectively. In our ICCP system used in this study (see Figure 5(a)), the wires were welded to the steel rebars, and the completed thermite welds were coated. As for the connection between CF-MESH anode and power supply positive cable, the CF-MESH was embedded between two connection plates by bolts, and the power supply cable afterwards were connected to the plates by clips at appropriate distance (see Figure 5(b)). This is a metal-to-metal connection to ensure that the cathode network is electrically continuous. Wires were protected with a plastic sleeve/tube at points where they bend. In order to verify the quality of all 
271

272

connections, electrical testing for continuity were conducted and documented according to ICCP-SS standard (EN 12696, 2000). The tests were terminated after 60 days for safety reason, since the ICCP code - NACE TM0105 (NACE, 2016) specifies the maximum voltage as $20 \mathrm{~V}$ in the practical projects. Constant currents were applied by adjusting the driving voltage of the power supply to provide cathodic protection for the rebars.

The impressed current density is a key parameter in the ICCP technique. This study adopted four different anodic current densities $-0 \mathrm{~mA} / \mathrm{m}^{2}$ (reference specimen), $26 \mathrm{~mA} / \mathrm{m}^{2}, 80 \mathrm{~mA} / \mathrm{m}^{2}$ and $400 \mathrm{~mA} / \mathrm{m}^{2}$, resulting in four corresponding cathodic current densities - 0, 20, 62 and $312 \mathrm{~mA} / \mathrm{m}^{2}$. For each current density, four identical specimens were prepared to conduct parallel tests. The labeling of the specimens indicates anodic current densities, as shown in Table 5; for example, specimen "I80-a" represents the applied current density of $80 \mathrm{~mA} / \mathrm{m}^{2}$. The second part "a", "b", "c" and "d" relates to the four parallel test specimens.

The maximum cathodic current density has been specified as $20 \mathrm{~mA} / \mathrm{m}^{2}$ in the design codes and the relevant literature (EN12696, 2000; Araujo et al 2013; Bertolini et al. 2013). Therefore, this cathodic current density was adopted in this project for the I26 specimens. Meanwhile, the tests of I80 and I400 specimens were accelerated tests with the current densities of $80 \mathrm{~mA} / \mathrm{m}^{2}$ and $400 \mathrm{~mA} / \mathrm{m}^{2}$, which is a methodology to investigate the durability of the performance of ICCP in corroded RC structures. The purpose is to simulate the long-term performance of real structures subjected to the codified charge quantities by using relatively large current densities within a reasonable period. For specimens I26, I80 and I400, a current density of $26 \mathrm{~mA} / \mathrm{m}^{2}, 80 \mathrm{~mA} / \mathrm{m}^{2}$ and $400 \mathrm{~mA} / \mathrm{m}^{2}$ was applied to the specimens for 60 days. The total charge quantity can be calculated by multiplying the current density with time. While in practical cases with the current density of 
293

$26 \mathrm{~mA} / \mathrm{m}^{2}$, the equivalent cathodic protection duration for these specimens are calculated to be 60 , 185 and 923 days based on the same charge quantity.

During the ICCP, the instant-off potential of the embedded steel, the 4-hour decay potential value and the feeding voltage between the C-FRCM composite and the rebars were recorded by the embedded reference electrode and the electrochemical signal acquisition instrument (MEMORY HiLOGGER LR8400-21). After the cathodic protection, single shear tests were conducted on the specimens by displacement control, with the loading rate as $0.08 \mathrm{~mm} / \mathrm{min}$. The same measurements were recorded as in the previous tests. Afterwards, a phenolphthalein reagent was sprayed onto the surface of the anodic material so that the changes to the interface could be observed.

\section{Results and discussion}

\section{Protection conditions due to ICCP technique}

A layer of CF-MESH was bonded onto the surface of concrete cubes using the WC-1 cementitious matrix and a certain amount of constant current was applied to the specimens. Fig. 6 shows the changes of the feeding voltage between the CF-MESH (i.e. anode) and the rebars (i.e. cathode) of the specimens. The feeding voltage is the product of constant current and electric resistance along the circuit. Since constant currents were used in this study to provide cathodic protection, the changes in the feeding voltage is caused by the electric resistance of the circuit, which is very likely due to the deterioration of the CFRP/cementitious material interface. The specimens (I400) with a current density of $400 \mathrm{~mA} / \mathrm{m}^{2}$ have a higher feeding voltage than the specimens (I26 and I80) with a $26 \mathrm{~mA} / \mathrm{m}^{2}$ or $80 \mathrm{~mA} / \mathrm{m}^{2}$ current density. The initial feeding voltage of specimens $\mathrm{I} 26$ 
and I80 were found to be less than $3 \mathrm{~V}$, but around $6 \mathrm{~V}$ for specimen I400. During the tests, the feeding voltages of the specimens with low current densities remained stable. After 60 days, the feeding voltage of specimens I26 and I80 were no greater than $7 \mathrm{~V}$, while the feeding voltage of specimens I400 could reach up to $20 \mathrm{~V}$. The results of the feeding voltage showed that under low current density conditions $\left(26 \mathrm{~mA} / \mathrm{m}^{2}\right.$ or $\left.80 \mathrm{~mA} / \mathrm{m}^{2}\right)$, the feeding voltage was relatively stable (i.e. 2 - $6 \mathrm{~V}$ ) and the ICCP-SS system was in a good condition, while under a greater current density $\left(400 \mathrm{~mA} / \mathrm{m}^{2}\right)$, the impedance of the RC structures increased significantly due to an increase of the polarization in the anodic surface, and the feeding voltage also increased greatly (i.e. 6 - 20 V), showing that the workability of the system might become poor.

The protection conditions of rebars subjected to the ICCP-SS technique using the C-FRCM were indicated by the instant-off potential value and 4-hour delay potential value of the steel bars from tests (NACE SP0290, 2007; NACE 35108, 2008). The 4-hour delay potential values of all specimens greatly exceeded $100 \mathrm{mV}$ (see Fig. 7(a)); according to the requirements of the codes, this shows that the rebars were protected successfully by using the ICCP-SS technique. The cathodic protection potential of the specimens under the lower current densities $\left(26 \mathrm{~mA} / \mathrm{m}^{2}\right.$ and 80 $\left.\mathrm{mA} / \mathrm{m}^{2}\right)$ all reached the lower boundary of the protection potential value $(-0.57 \mathrm{~V})$ as specified in the code EN12954 (2001), and were not greater than the upper boundary of the protection potential value (-1.12 V), as shown in Fig. 7(b). Again, the comparison of the measured value with the criteria specified in the codes shows the embedded reinforcement has been fully protected. The cathodic protection value of the I400 specimens passed the greatest protection potential value, indicating that the $400 \mathrm{~mA} / \mathrm{m}^{2}$ current density would provide over-protection for the reinforcement for most of the practical cases with reinforcement ratio smaller than $2.68 \%$, causing hydrogen 
embrittlement in the interface (Bertolini et al., 2013).

In summary, using WC-1 cementitious matrix as the bonding material and CF-MESH as the anode would be able to provide effective cathodic protection for reinforcement in RC structures. It should also be noted that the current density used in the protection should comply with the codified current density.

\section{Shear stress transfer behavior due to the SS technique}

The single shear test results of the specimens after a 60-day cathodic protection are shown in Table 4 and a comparison of their shear strengths is shown in Fig. 8. With an increase in the applied current density, the shear strength between the C-FRCM and concrete decreased and, meanwhile, the failure mode changed for the largest current density. When the current is not applied (I0), which is the conventional structural strengthening case, the shear strength was 2.09 MPa. With low current densities (I26 and I80), the shear strengths were found to be $2.05 \mathrm{MPa}$ and 1.93 $\mathrm{MPa}$, respectively, which decreased by $1.9 \%$ and $7.7 \%$ compared with the specimens in series I0. When the current density was $400 \mathrm{~mA} / \mathrm{m}^{2}$, the shear strength decreased to $1.83 \mathrm{MPa}$, which was $12.4 \%$ less compared with that of the specimens in series I0. The failure modes also changed: the failure mode of the specimens in series I0, I26 and I80 was debonding within the concrete (DB), as shown in Fig. 9(a), 9(b) and 9(c), respectively; the failure mode of the I400 specimens was a combination of debonding within the concrete and matrix failure between the CF-MESH and the cementitious matrix (DB + CB), as shown in Fig. 9(d).

After the single shear tests, a phenolphthalein reagent was sprayed onto the anodic surface to assess the acidity and alkalinity of the anodic interface. It showed red (alkalinity) for specimens I0, 
359

360

361

362

363

364

365

I26 and I80, and an unclear or transparent color (acidity) for specimen I400, as presented in Fig.

10, which indicates anodic acidification has occurred in specimen I400 due to the large current density applied. It has been well discussed in literature (Bertolini et al., 2013) that deterioration will be caused by anodic polarization, with anodic acidification being the most significant case of anodic polarization. This is the reason why the shear strengths deceased with the applied charge densities, and in the most serious case (I400), the failure mode also changed. It is also found that the deterioration of the shear strength in the conditions of the present study is not as significant as that in other environments (Gamage et al., 2005; Al-Rousan et al., 2013). It can be seen that even in the worst case in this study (i.e. applying 20 times the standard current density for 60 days), the deterioration of the shear strength is relatively minor, which may still satisfy the structure strengthening requirement.

\section{Discussion on durability}

As mentioned above, besides the tests on the $\mathrm{I} 26$ specimens that adopted the maximum current density specified in the code, two series of accelerated tests (specimens I80 and I400) were also conducted. The purpose was to simulate, within a reasonable period, the long-term performance of real structures subjected to codified current densities by using relatively large current densities (4 and 20 times of the standard current density). Based on an equal charge quantity (i.e. the total applied charge quantities in the accelerated and normal conditions are the same), the protection period of specimens I26, I80 and I400 was equal to 60, 185 and 923 days, and the degradation of the shear strength was $1.9 \%, 7.7 \%$ and $12.4 \%$, respectively. It should be noted that the shear strength of the specimens in the I400 series was also able to satisfy the requirements for structural 
381

strengthening after the accelerated ICCP period, though the failure mode $(\mathrm{DB}+\mathrm{CB})$ departed from the expected failure mode of the CFRP-strengthened RC structures.

In terms of durability investigation, the accelerated tests are commonly used in research investigating the efficiency of the cathodic protection technique, which mainly focuses on the corrosion of rebar (Cramer et al., 2002; García et al., 2012; Anwar et al., 2014; Lu et al., 2018; Bhuiyan et al., 2018). If the relation between an accelerated test and a normal operation condition can be identified, the results from an accelerated test can be easily converted to any specific current density level. For this purpose, based on the principle of equal charge quantity (Chang et. al., 1999, Anwar et al. 2014), the accelerated tests using large current densities could be treated as identical to the real situation in practice under smaller current densities for a longer time. However, this study on ICCP-SS considers both the corrosion of rebar as well as the structural performance of the interface. When considering the bond behavior, larger current density applied within a shorter period might result in more serious deterioration in a structure compared to smaller current density applied to the same structure within a longer period, especially when anodic acidification occurs (Zhang et al. 2016, Zhu et al. 2017, Zhang et al. 2018). Therefore, results from accelerated exposure tests cannot be directly correlated to natural exposures. The actual results for structures subjected to the codified current density (i.e. $20 \mathrm{~mA} / \mathrm{m}^{2}$ cathodic current density) for around 3 years can be expected to be more optimistic than the test results (of specimen I400) obtained in this study. In the future application of ICCP-SS, the impressed current density should be chosen carefully in order to obtain optimized performance.

\section{Conclusions}


The research outcomes include:

(1) In order to combine cathodic protection and structural strengthening for reinforced concrete subjected to a chloride-induced corrosion environment, this study investigated the mechanical behavior of conductive polymer-modified cementitious matrices. Based on an assessment of conductivity, flexural, compressive and shear strengths, this study found the optimized ingredients of cementitious material, which contains redispersible latex powder $(20 \%$ of the mass of cement and silica fume) and short chopped carbon fibers (1\% of the mass of cement), as well as other mixtures (superplasticizer, CMC and defoamer).

(2) Based on the optimized cementitious matrix and carbon fiber mesh (CF-MESH), the impressed current cathodic protection - structural strengthening (ICCP-SS) technique was developed. The experimental program adopted a variety of impressed current densities from 20 to $400 \mathrm{~mA} / \mathrm{m}^{2}$. The ICCP-SS technique was found to be capable of providing effective cathodic protection for reinforcements. In addition, the cathodic applied current density of $20 \mathrm{~mA} / \mathrm{m}^{2}$ codified in the international standards of ICCP for RC structures has been found to be effective for the proposed ICCP-SS system.

(3) After ICCP, single shear tests were conducted on the specimens. The test results showed that shear strength degraded with increased charge density due to anodic polarization. In the most serious case $\left(400 \mathrm{~mA} / \mathrm{m}^{2}\right)$, the occurrence of anodic acidification led to the change of failure mode in the C-FRCM-concrete interface from debonding within the concrete (DB) to a combination failure $(\mathrm{DB}+\mathrm{CB})$. However, even for specimen $\mathrm{I} 400$, the shear strength, which was $12.4 \%$ less than the reference specimens $\left(0 \mathrm{~mA} / \mathrm{m}^{2}\right)$, might still be able to satisfy structural strengthening requirements. 
425 (4) The results show that it is feasible to use the new composite of CF-MESH with carbon fiber 426 reinforced cementitious matrix (C-FRCM composite) as a dual-functional material for the 427 combined cathodic protection and structural strengthening of reinforced concrete structures in 428 chloride-contaminated environments for a reasonably long period. Note that the applied current 429 density should be chosen carefully according to the cathodic protection codes, as overlarge current density might result in deterioration in the early stage.

\section{Acknowledgements}

433 The research work described in this paper was supported by the National Natural Science 434 Foundation of China (Project No.: 51538007, 51478269, 51508336).

\section{References}

ACI (American Concrete Institute). (2001). "Protection of Metals in Concrete Against Corrosion." ACI 222R-01, Farmington Hills, MI.

ACI 549.4R-13 (2013). "Guide to design and construction of externally bonded fabric-reinforced cementitious matrix (FRCM) systems for repair and strengthening concrete and masonry structures.” American Concrete Institute.

AC434 (2016). “Acceptance Criteria for Masonry and Concrete Strengthening Using Fabric-Reinforced Cementitious Matrix (FRCM) and Steel Reinforced Grout (SRG) Composite Systems.” International Code Council, Evaluation Service, (ICC ES).

Al-Rousan, R., Haddad, R., and Al-Sa'di, K. (2013). "Effect of sulfates on bond behavior between carbon fiber reinforced polymer sheets and concrete.” Materials \& Design, 43, 237-248. 
anode for impressed current cathodic protection of steel reinforced concrete application." Construction and Building Materials, 71(30), 167-180.

450

451

452

453

ASTM (American Society for Testing Materials) (1990). "The Threshold Concentration of Chloride in Concrete for the Initiation of Reinforcement Corrosion." ASTM STP1065, West Conshohocken, PA, USA.

Araujo, A., Panossian, Z., and Lourenço, Z. (2013). "Cathodic protection for concrete structures." Revista IBRACON de Estruturas e Materiais, 6(2), 178-193.

Awani, O., El-Maaddawy, T., and Ismail, N. (2017), "Fabric-reinforced cementitious matrix: a promising strengthening technique for concrete structures", Construction \& Building Materials, 132(1): 94-111.

Badanoiu, A., and Holmgren, J. (2003). "Cementitious composites reinforced with continuous carbon fibres for strengthening of concrete structures." Cement and Concrete Composites, 25(3), 387-394.

Bertolini, L., Elsener, B., Pedeferri, P., Redaelli, E., and Polder, R. B. (2013). Corrosion of steel in concrete: prevention, diagnosis, repair, John Wiley \& Sons, Hoboken, New Jersey, USA.

Bhuiyan, S., Law, D. W., Nicholls, P., and Christodoulou, C. (2018). "Investigation of the residual protection of steel following application of protective current." Construction and Building Materials, 162(20), 503-511.

BS (British Standards). (2000). "Cathodic protection of steel in concrete.” EN 12696:2000, UK.

BS (British Standards). (2001). “Cathodic Protection of Buried or Immersed Metallic Structures General Principles and Application for Pipelines.” EN 12954:2001, UK.

BS (British Standards). (2005). "Methods of testing cement - Part 1: Determination of strength." 
471

Carloni C, D’Antino T, Sneed L H, and Pellegrino. C. (2015). "Role of the matrix layers in the stress-transfer mechanism of FRCM composites bonded to a concrete substrate." Journal of Engineering Mechanics, 10.1061/(ASCE)EM 1943-7889. 0000883, (2015)141:6(04014165), $1-10$

Chang J J, Yeih W, Huang R. (1999). "Degradation of the bond strength between rebar and concrete due to the impressed cathodic current." Journal of Marine Science \& Technology, $7(2): 89-93$.

Chen, B., Wu, K., and Yao, W. (2004). "Conductivity of carbon fiber reinforced cement-based composites.” Cement and Concrete Composites, 26(4), 291-297.

Chung, D. (2000). "Cement reinforced with short carbon fibers: a multifunctional material." Composites Part B: Engineering, 31(6), 511-526.

Cramer, S. D., Jr, B. S. C., Bullard, S. J., Holcomb, G. R., Russell, J. H., and Nelson, F. J., et al. (2002). "Corrosion prevention and remediation strategies for reinforced concrete coastal bridges." Cement and Concrete Composites, 24(1), 101-117.

D’Ambrisi, A., Feo, L., and Focacci, F. (2013). "Experimental and analytical investigation on bond between Carbon-FRCM materials and masonry." Composites Part B: Engineering, 46, 15-20.

D'Ambrisi, A., Focacci, F., Luciano, R., Alecci, V., and De Stefano, M. (2015). "Carbon-FRCM materials for structural upgrade of masonry arch road bridges." Composites Part B: Engineering, 75, 355-366.

D’Ambrisi, A., and Focacci, F. (2011). "Flexural strengthening of RC beams with cement-based 
D’Ambrisi, A., Feo, L., and Focacci, F. (2013). "Experimental analysis on bond between PBO-FRCM strengthening materials and concrete.” Composites Part B: Engineering, 44(1), $524-532$.

Dai, J., Ueda, T., Sato, Y., and Ito, T. (2005). "Flexural strengthening of RC beams using externally bonded FRP sheets through flexible adhesive bonding." Proc., Proceedings of the International symposium on bond behavior of FRP in structures (BBFS 2005), Chen and Teng, eds., Hong Kong, 205-213.

Dong, Z., Wu, G., and Xu, Y. (2016). "Experimental study on the bond durability between Construction and Building Materials, 115, 277-284.

Escrig, C., Gil, L. and Bernat-Maso, E. (2017), "Experimental comparison of reinforced concrete

Gamage, J., Wong, M.-B., and Al-Mahaidi, R. (2005). "Performance of CFRP strengthened

García, J., Almeraya, F., Barrios, C., Gaona, C., Núñez, R., and López, I., et al. (2012). “Effect of cathodic protection on steel-concrete bond strength using ion migration measurements." Cement and Concrete Composites, 34(2), 242-247. 
ISO-12696 (2016), Cathodic protection of steel in concrete, published in Switzerland, 2016-12-1.

JSCE (Japan Society of Civil Engineers). (2008). "Recommendations for Design and Construction of High Performance Fiber Reinforced Cement Composites with Multiple Fine Cracks (HPFRCC).” Concrete Engineering Series 82, Japan.

Kabir, M. I., Shrestha, R., and Samali, B. (2016). "Effects of applied environmental conditions on the pull-out strengths of CFRP-concrete bond." Construction and Building Materials, 114, 817-830.

Lambert, P., Van Nguyen, C., Mangat, P. S., O’Flaherty, F. J., and Jones, G. (2015). “Dual function carbon fibre fabric strengthening and impressed current cathodic protection (ICCP) anode for reinforced concrete structures." Materials and Structures, 48(7), 2157-2167.

Lu, Y. Y., Hu, J. Y., Li, S., and Tang, W. S. (2018). "Active and passive protection of steel reinforcement in concrete column using carbon fibre reinforced polymer against corrosion." Electrochimica Acta, 278(10), 124-136.

Mehta, P. (1991). "Durability of Concrete - Fifty Years of Progress.” Proc., Durability of Concrete Second International Conference, Montreal, QC, Canada, 1-32.

Michel, A., Pease, B. J., Peterová, A., Geiker, M. R., Stang, H., and Thybo, A. E. A. (2014), "Penetration of corrosion products and corrosion-induced cracking in reinforced cementitious materials: experimental investigations and numerical simulations", Cement \& Concrete Composites, 47(6): 75-86.

NACE International (National Association of Corrosion Engineers). (2007). "Impressed current cathodic protection of reinforcing steel in atmospherically exposed concrete structures." NACE SP0290-2007, Houston, TX. 
NACE International (National Association of Corrosion Engineers). (2008). “One Hundred Millivolt (mV) Cathodic Polarization Criterion." NACE International Publication 35108, Houston, TX.

NACE International (National Association of Corrosion Engineers). (2016). "Evaluation of Coatings Containing Conductive Carbon Pigmentation for Use as an Anode on Atmospherically Exposed Reinforced Concrete.” NACE TM0105-2016, Houston, TX.

Nguyen, C. V., Lambert, P., Mangat, P., O’Flaherty, F., and Jones, G. (2012). "The performance of carbon fibre composites as ICCP anodes for reinforced concrete structures." ISRN Corrosion, $2012,1-9$

Ombres , L. (2015), “Analysis of the bond between Fabric Reinforced Cementitious Mortar (FRCM) strengthening systems and concrete." Cmposites Part B: Engineering, 69, 418-426.

Pedeferri, P. (1996). "Cathodic protection and cathodic prevention.” Construction and Building Materials, 10(5), 391-402.

Raupach, M. (1996). "Chloride-induced macrocell corrosion of steel in concrete-theoretical background and practical consequences." Construction and building materials, 10(5), 329-338.

RILEM TC 201-TRC, (2006), “Textile Reinforced Concrete - State-of-the-Art Report”, Edited by W. Brameshuber, ISBN: 2-912143-99-3.

RILEM TC 232-TDT, (2016), “Test methdos and design of texitle reinforced concrete.” Material and Structures, (2016) 49: 4923-4927.

Saadatmanesh, H., and Malek, A. M. (1998). "Design guidelines for flexural strengthening of RC beams with FRP plates." Journal of Composites for Construction, 
Shi, J., Ming, J., Zhang, Y., and Jiang, J. (2018), “Corrosion products and corrosion-induced cracks of low-alloy steel and low-carbon steel in concrete", Cement \& Concrete Composites, 88: $121-129$.

Sun, H., Guo, G., Memon, S., Zhu, J.-H., Xing, F. (2015). "Recycling of carbon fibers from carbon fiber reinforced polymer using electrochemical method.” Composites Part A: Applied Science and Manufacturing, 78, 10-17.

Tran, C. T. M., Stitmannaithum, B., and Ueda, T. (2014). "Investigation of the bond behaviour

Ueda, T., and Dai, J. (2005). "Interface bond between FRP sheets and concrete substrates: properties, numerical modeling and roles in member behaviour." Progress in Structural

Verma A. and Goyal S. (2015), “Cathodic Protection of Corroded Pre-stressing Tendon by CFRP Concrete Structures, Shenzhen, Guangdong, P.R.China, pp.300-308. 

Materials, 185, 57-68.

582 Zhao, Y., Dong, J., Wu, Y., and Jin, W. (2016), "Corrosion-induced concrete cracking model considering corrosion product-filled paste at the concrete/steel interface", Construction \& Building Materials, 116(30): 273-280.

Zhu, J., Zhu, M., Han, N., Xing, F., Liu, W., and Bertolini, L. (2014a). "Behavior of CFRP Plate in Simulated ICCP System of Concrete Structures." Proc., 4th International Conference on the Durability of Concrete Structures., Purdue University, West Lafayette, IN, USA, 363-368.

Zhu, J.H., Zhu, M., Han, N., Liu, W., and Xing, F. (2014b). "Electrical and mechanical performance of carbon fiber-reinforced polymer used as the impressed current anode material." Materials, 7(8), 5438-5453.

Zhu, J.H., Wei, L., Wang, Z., Liang, C., Fang, Y., Xing, F. (2016). "Application of carbon-fiber-reinforced polymer anode in electrochemical chloride extraction of steel-reinforced concrete." Construction and Building Materials, 120, 275-283.

Zhu, J. H., Wei, L.L., Moahmoud, H., Redaelli, E, Xing, F., Bertolini, Luca, (2017), “Investigation on CFRP as dual-functional material in chloride - contaminated solutions." Construction and Building Materials, 151: 127-137. 